Supporting Information

\title{
Pyrolysis Creates Electron Storage Capacity of Black Carbon (Biochar) from Lignocellulosic Biomass
}

\author{
Danhui Xin ${ }^{\dagger}$, Nepu Saha $a^{+}$, M. Toufiq Rezat, Jeffrey Hudson ${ }^{\dagger}$, Pei C. Chiu ${ }^{\dagger *}$ \\ ${ }^{\dagger}$ Department of Civil and Environmental Engineering, University of Delaware, 221 Academy \\ Street, Newark, DE 19716 \\ $\$$ Department of Biomedical and Chemical Engineering and Sciences, Florida Institute of \\ Technology, 150 W University Blvd, Melbourne, FL 32901
}

\section{*Corresponding Author}

Pei C. Chiu- Department of Civil and Environmental Engineering, University of Delaware, 221 Academy Street, Newark, DE 19716; Email: pei@udel.edu; https://orcid.org/0000-0003$\underline{2319-4496}$

\section{Summary (19 pages; 7 tables; 8 figures)}

The Supporting Information contains summary tables of samples, ESC measurements of biopolymers by CRT with Ti(III) citrate, characterization results from proximate analysis, iron content measurement, ultimate analysis, and ss-NMR spectroscopy, and biochar ESC data by MEA compiled from the literature. 
Table S1. Summary of the feedstocks and corresponding biochars characterized in this study.

\begin{tabular}{llllll}
\hline Pyrolysis Temperature $\left({ }^{\circ} \mathrm{C}\right)$ & - & 350 & 450 & 550 & 650 \\
\hline Cellulose & $\underline{\mathbf{C}}$ & C350 & $\underline{\mathbf{C 4 5 0}}$ & C550 & C650 \\
Xylan & $\underline{\mathbf{X}}$ & X350 & $\underline{\mathbf{X 4 5 0}}$ & X550 & X650 \\
Lignin & $\underline{\mathrm{L}}$ & $\underline{\mathrm{L} 350}$ & $\underline{\mathbf{L 4 5 0}}$ & $\underline{\text { L550 }}$ & $\underline{\underline{\text { L650 }}}$ \\
Wood & $\underline{\mathrm{W}}$ & W350 & $\underline{\mathbf{W 4 5 0}}$ & W550 & W650 \\
Mixture of Biopolymers & $\mathrm{M}$ & M350 & M450 & M550 & M650 \\
\hline
\end{tabular}

M consisted of $58.4 \%$ cellulose, $13.7 \%$ xylan, and $27.9 \%$ lignin by mass. The ESC of feedstocks was measured by MEA, whereas the ESC of biochars were measured by CRT. The ESC of selected samples (bold) was measured by both MEA and CRT. Selected samples (underlined) were characterized by ss-NMR.

Table S2. Information of black carbon samples assessed by CRT with Ti(III) citrate

\begin{tabular}{|c|c|c|c|}
\hline & Vendor/Sampling Location & $\begin{array}{l}\text { Pyrolysis } \\
\text { Temperature } \\
\left({ }^{\circ} \mathrm{C}\right)\end{array}$ & Comments \\
\hline Graphite & Alfa Aesar (Haverhill, MA) & - & Purity $99.9999 \%$ \\
\hline SRB & The Biochar Company (PA) & 550 & \\
\hline CB 1 & - & 450 & Donation from CA \\
\hline CB 2 & $\begin{array}{l}\text { Biochar Engineering } \\
\text { Corporation }(\mathrm{CO})\end{array}$ & 600 & $\begin{array}{l}\text { A biochar sample used in the } \\
\text { study by Gomez-Eyles et al. }\end{array}$ \\
\hline CB 3 & $\begin{array}{l}\text { Organic Soil Science Biochar } \\
\text { (CA) }\end{array}$ & 750 & Fast pyrolysis \\
\hline CB 4 & Oregon Biochar Solutions (OR) & 900 & Fast pyrolysis \\
\hline CB 5 & Oregon Biochar Solutions (OR) & 950 & Fast pyrolysis \\
\hline $\begin{array}{l}\text { Wildfire } \\
\text { Char } 1\end{array}$ & $\begin{array}{l}34^{\circ} 09^{\prime} 07.7^{\prime \prime} \mathrm{N} 118^{\circ} 57^{\prime} 06.3^{\prime \prime} \mathrm{W} \\
\text { (Newbury Park, CA) }\end{array}$ & - & $\begin{array}{l}\text { Fire started on Oct. 10, 2019, } \\
\text { char sampled in Jan. } 2020^{2}\end{array}$ \\
\hline $\begin{array}{l}\text { Wildfire } \\
\text { Char } 2\end{array}$ & $\begin{array}{l}34^{\circ} 15^{\prime} 17.8^{\prime \prime} \mathrm{N} 118^{\circ} 48^{\prime} 58.9^{\prime \prime} \mathrm{W} \\
\text { (Simi Valley, CA) }\end{array}$ & - & $\begin{array}{l}\text { Fire started on Oct. } 30,2019 \text {, } \\
\text { char sampled in Jan. } 2020^{2}\end{array}$ \\
\hline
\end{tabular}

CB stands for commercial biochar. All CBs are derived from pine wood. All biochars were ground to have a particle size $<53 \mu \mathrm{m}$ before ESC measurement by CRT. 
Supporting Information

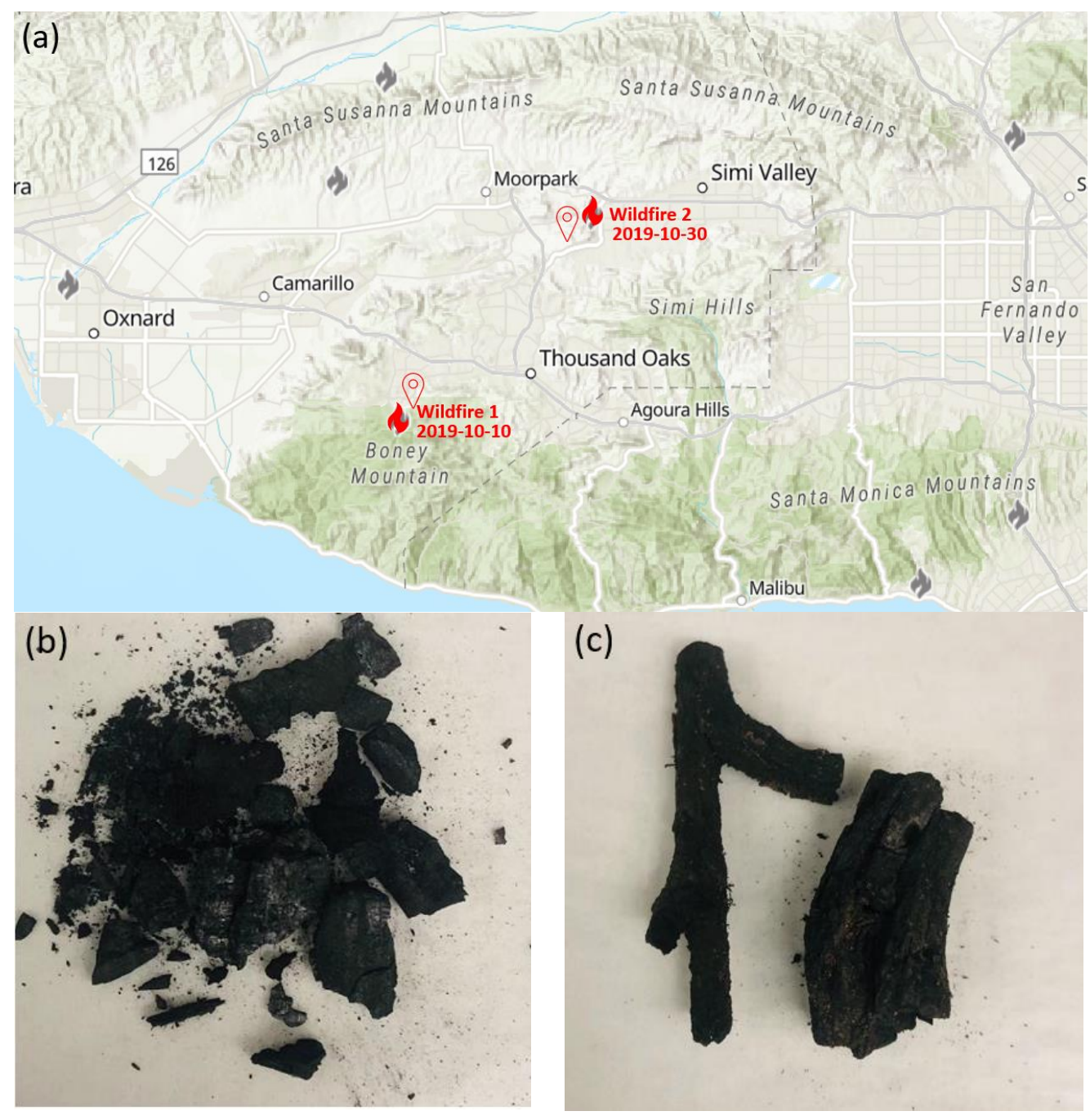

Figure S1. (a) Locations of fire events and their start time, and sampling. (b) Image of Wildfire Char 1 (c) Image of Wildfire Char 2 
Supporting Information

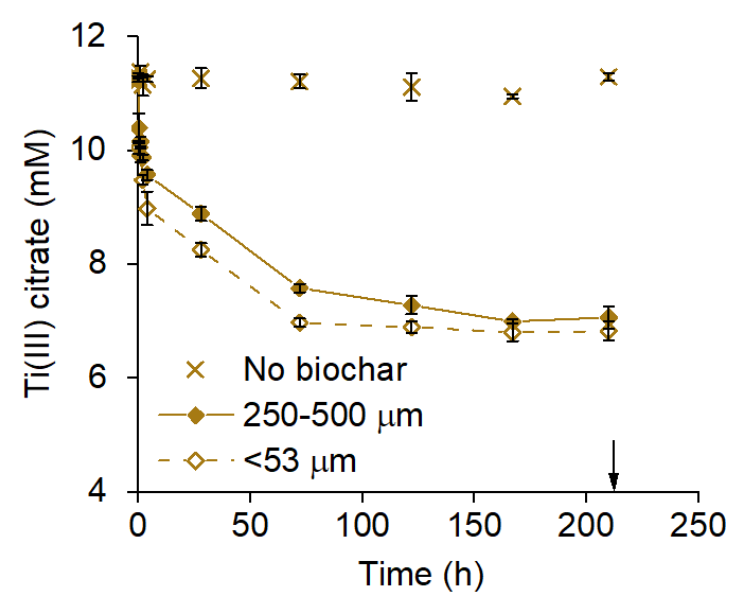

Figure S2. Reduction of DO-oxidized SRB by Ti(III) citrate as a function of time. At the end of experiment $(\downarrow, 210 \mathrm{~h})$, total titanium (Ti(III)+Ti(IV)) concentration in each reactor was quantified by ICP-MS. Total Ti concentrations in the $250-500 \mu \mathrm{m},<53 \mu \mathrm{m}$, and no biochar reactors were $11.11 \pm 0.27,11.38 \pm 0.05$, and $11.19 \pm 0.20 \mathrm{mM}$, respectively.
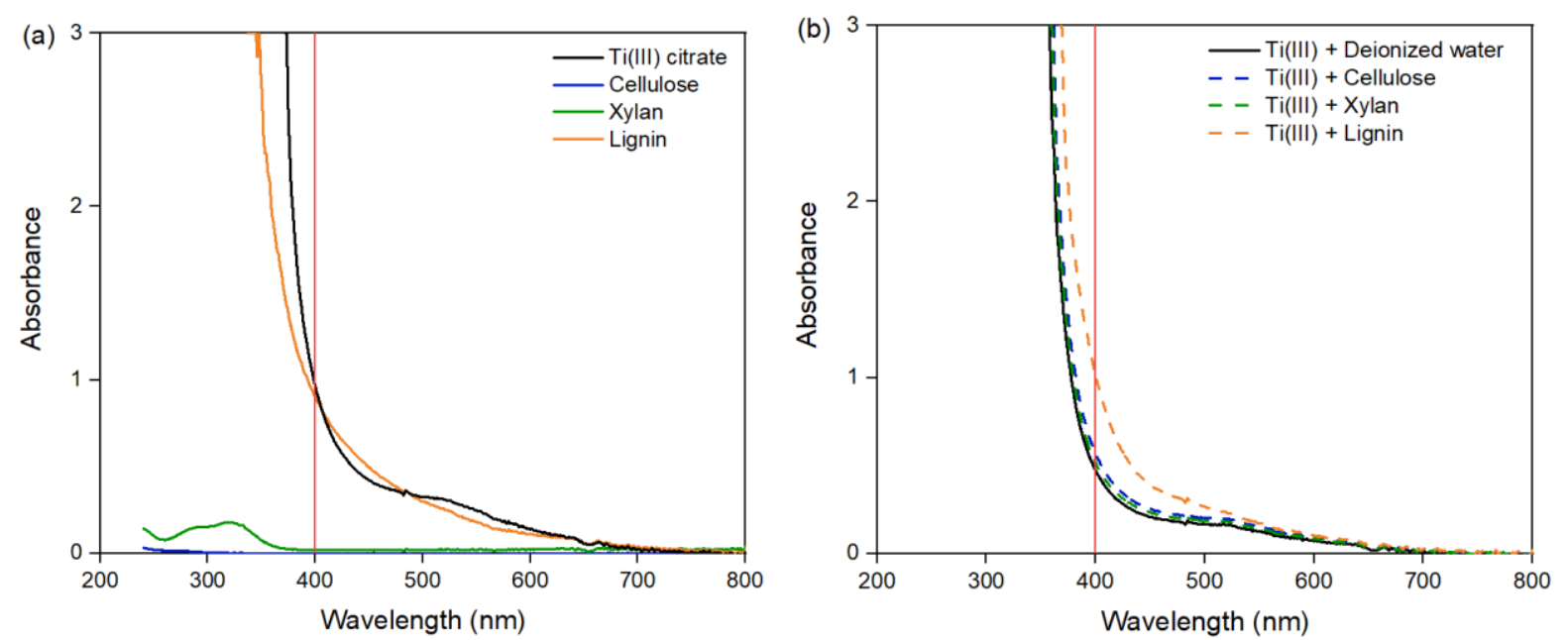

Figure S3. (a) UV-vis spectra of $10.6 \mathrm{mM}$ Ti(III) citrate, $1 \mathrm{~g} / \mathrm{L}$ DO-oxidized cellulose, 1 g/L DOoxidized xylan, and $0.25 \mathrm{~g} / \mathrm{L}$ DO-oxidized lignin. (b) UV-vis spectra of solutions containing $5 \mathrm{~mL}$ of $10.6 \mathrm{mM}$ Ti(III) citrate mixed with $5 \mathrm{~mL}$ of deionized water, $1 \mathrm{~g} / \mathrm{L}$ DO-oxidized cellulose or xylan, or $0.25 \mathrm{~g} / \mathrm{L}$ DO-oxidized lignin. 


\section{Section S1. Proximate Analysis of Feedstocks}

Proximate analysis, i.e., assessment of the content of volatile matter, fixed carbon, and ash, was performed by thermogravimetric analyses (TGA) using TGA Q500 from TA Instruments (New Castle, DE). The sample heating rate and gas flow rate were set at $20^{\circ} \mathrm{C} / \mathrm{min}$ and 50 $\mathrm{mL} / \mathrm{min}$, respectively. A nitrogen atmosphere was used for determining the volatile matter. Samples were heated from 25 to $105^{\circ} \mathrm{C}$ and held at $105{ }^{\circ} \mathrm{C}$ for $5 \mathrm{~min}$, and then heated to $900{ }^{\circ} \mathrm{C}$ and held at $900{ }^{\circ} \mathrm{C}$ for another $5 \mathrm{~min}$. To further determine fixed carbon and ash contents, the air was introduced to combust the remaining sample at $900{ }^{\circ} \mathrm{C}$ for $10 \mathrm{~min}$. Mass remaining at the end of the combustion process was taken to be ash, and fixed carbon was obtained by subtracting volatile and ash contents from $100 \%$.

Table S3. Proximate analysis of feedstocks

\begin{tabular}{llll}
\hline & Volatile Matter $(\%)$ & Fixed Carbon $(\%)$ & Ash $(\%)$ \\
\hline Cellulose & $97.8 \pm 0.1$ & $2.2 \pm 0.1$ & BD \\
Xylan & $88.1 \pm 0.4$ & $11.9 \pm 0.4$ & BD \\
Lignin & $48.7 \pm 1.5$ & $39.9 \pm 0.0$ & $11.5 \pm 1.5$ \\
Wood & $88.5 \pm 0.2$ & $11.5 \pm 0.2$ & BD \\
\hline
\end{tabular}

BD: below detection. Errors show the range of values from duplicates. 


\section{Section S2. Iron Contents of Samples Containing Lignin}

Given an ash content of $11.5 \%$ in the commercial lignin (Table S3), inorganic elements such as redox-active metals may be present in samples containing lignin and thus contribute to the observed EAC and/or EDC. To identify redox-active elements in those samples, elements from oxygen $(\mathrm{O})$ through uranium $(\mathrm{U})$ were scanned using a wavelength dispersive $\mathrm{X}$-ray fluorescence spectrometry (WDXRF, Rigaku Supermini 200, Tokyo, Japan). Analyses using WDXRF identified the presence of two redox-active elements, iron and sulfur, in lignin.

Iron contents of samples containing lignin (listed in Table S4) were further quantified by extraction with $1: 1 \mathrm{HNO}_{3}(\sim 35 \%){ }^{3}$ Specifically, $0.05 \mathrm{~g}$ of sample was shaken in $5 \mathrm{~mL}$ of $\mathrm{HNO}_{3}$ $(1: 100 \mathrm{w} / \mathrm{v})$ at $100 \mathrm{rpm}$ for $72 \mathrm{~h}$, and then diluted in a $25-\mathrm{mL}$ volumetric flask with deionized water. The diluted sample extracts were filtered with PVDF syringe filters prior to analysis using an ICP-MS. Results from ICP-MS following acid-digestion confirmed that the iron contents of lignin and biopolymer mixture were less than $0.03 \mathrm{mmol} / \mathrm{g}$, showing the contribution of iron to the ESC of samples containing lignin was negligible.

Table S4. Acid-extractable iron ( $\mathrm{mmol} / \mathrm{g})$ in samples containing lignin

\begin{tabular}{llll}
\hline L & $0.0173 \pm 0.0014$ & M & $0.0113 \pm 0.0046$ \\
L350 & $0.0119 \pm 0.0074$ & M350 & $0.0049 \pm 0.0010$ \\
L450 & $0.0285 \pm 0.0114$ & M450 & $0.0076 \pm 0.0007$ \\
L550 & $0.0167 \pm 0.0011$ & M550 & $0.0073 \pm 0.0037$ \\
L650 & $0.0209 \pm 0.0021$ & M650 & $0.0061 \pm 0.0016$
\end{tabular}

Errors show the range of values from duplicates.

We also prepared a $\mathrm{Na}^{+}$-exchanged lignin sample to eliminate the effect of redox-active metal cations on ESC. Specifically, $1 \mathrm{~g}$ of Amberlite ${ }^{\mathrm{TM}}$ (Alfa Aesar, Haverhill, MA) was added to a 
Supporting Information

solution containing $0.05 \mathrm{~g}$ of lignin $24 \mathrm{~h}$ prior to the experiment, and the solution was filtered with a cation exchange cartridge (Waters, Milford, MA) right before MEA analyses. MEA results confirmed that the ESC (EDC and EAC) of $\mathrm{Na}^{+}$-exchanged lignin were the same as untreated lignin. 
Supporting Information

\section{Section S3. Ultimate Analysis}

Carbon, hydrogen, nitrogen, sulfur, and oxygen contents were determined for ultimate analysis using a Flash 2000 Organic Elemental Analyzer from Thermo Scientific (Waltham, MA). Cystine sulphanilamide methionine BBOT was used as a calibration standard and vanadium oxide $\left(\mathrm{V}_{2} \mathrm{O}_{5}\right)$ was used as a conditioner. Fully dried samples were combusted at around $960{ }^{\circ} \mathrm{C}$ in ultra-high purity oxygen and passed through copper oxide pellets and then electrolytic copper with a helium carrier gas. The gases were then analyzed by a thermal conductivity detector (TCD). The detection limits for nitrogen and sulfur were $1.6 \%$ and $1.8 \%$, respectively. Oxygen content was calculated by subtracting carbon, hydrogen, nitrogen, and sulfur from $100 \%$.

Based on the elemental composition, mole ratios of $\mathrm{O} / \mathrm{C}$ and $\mathrm{H} / \mathrm{C}$ were calculated. In addition, aromaticity index $(\mathrm{AI})$, which is a measure of $\mathrm{C}=\mathrm{C}$ double bond density, ${ }^{4}$ was calculated based on Eq. S1.

$$
\mathrm{AI}=\frac{1+[C]-[O]-[S]-0.5[H]}{[C]-[O]-[S]-[N]}(\text { If } \mathrm{AI}<0, \text { then } \mathrm{AI}=0)
$$

where [element] is the mole content of the element in feedstock or biochar.

Ultimate analysis (Table S5) showed that the commercial lignin contained $3.36 \%(1.05 \mathrm{mmol} / \mathrm{g})$ sulfur, which was presumably incorporated through pulping (with $\mathrm{Na}_{2} \mathrm{~S}$ ) and acid precipitation (with $\mathrm{H}_{2} \mathrm{SO}_{4}$ ) during lignin extraction. Sulfate can make up about $45 \%$ of sulfur in lignin ${ }^{5}$ but would not contribute to EDC or EAC. Other inorganic (e.g., elemental sulfur and (poly)sulfides) and organic (e.g., sulfides) sulfur species, if present ${ }^{6}$ and reactive toward the oxidized form of ABTS (i.e., the radical ABTS $\cdot^{+}$), could have contributed to the observed EDC of lignin. 
Supporting Information

Table S5. Sulfur contents (mmol/g) of samples containing lignin

\begin{tabular}{llll}
\hline L & $1.05 \pm 0.01$ & M & $0.33 \pm 0.02$ \\
L350 & $0.76 \pm 0.03$ & M350 & $0.31 \pm 0.00$ \\
L450 & $0.60 \pm 0.01$ & M450 & $0.29 \pm 0.01$ \\
L550 & $0.67 \pm 0.02$ & M550 & $0.27 \pm 0.01$ \\
L650 & $0.68 \pm 0.01$ & M650 & $0.29 \pm 0.02$
\end{tabular}

Errors show the range of values from duplicates. Sulfur contents were calculated based on the results from ultimate analysis.

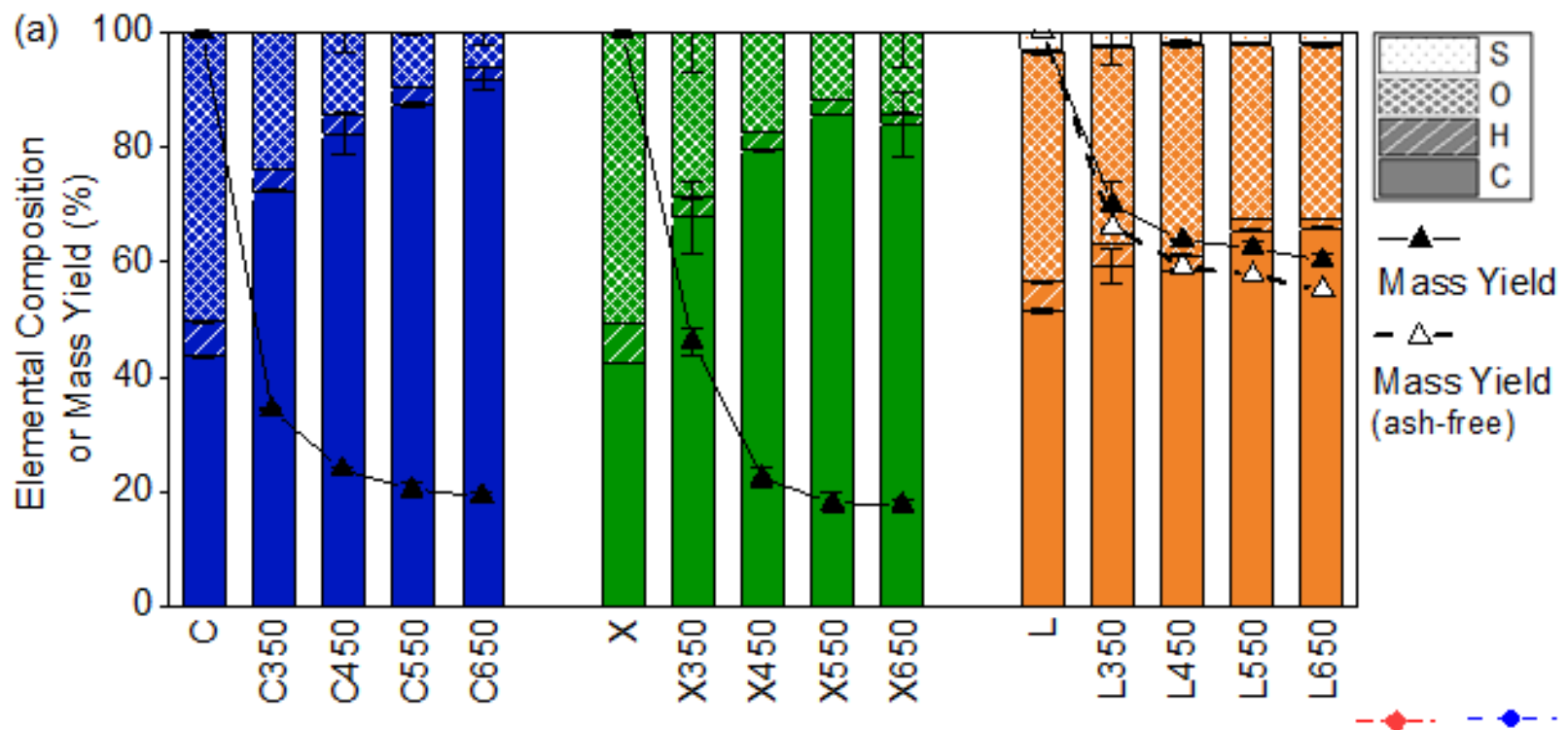

$[\mathrm{O}] / \mathrm{C}][\mathrm{H} /[\mathrm{C}]$

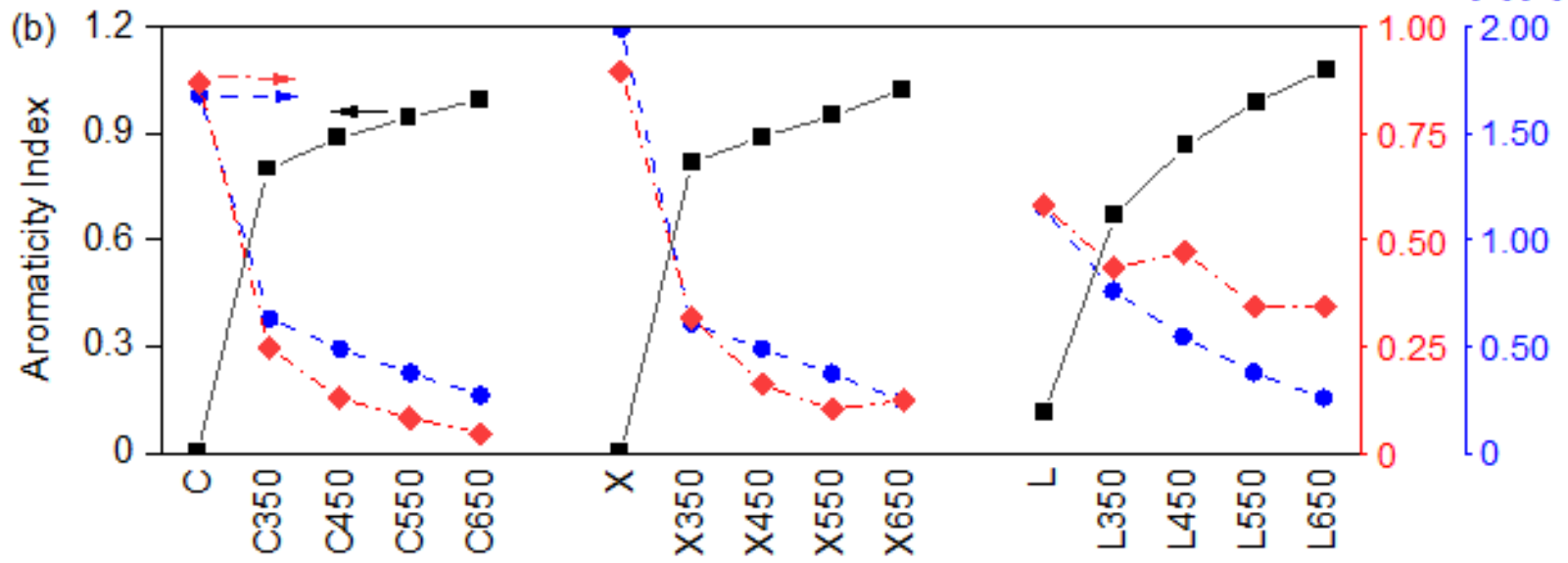

Figure S4. Characterization of three biopolymers and corresponding biochars from individual biopolymer pyrolysis. (a) Elemental composition (stacked columns) and mass-based yield. Open 
Supporting Information

diamonds represent the yields on an ash-free mass basis. (b) Aromaticity index and mole ratios of $\mathrm{O} / \mathrm{C}$ and $\mathrm{H} / \mathrm{C}$. Error bars represent the range of results from duplicates.

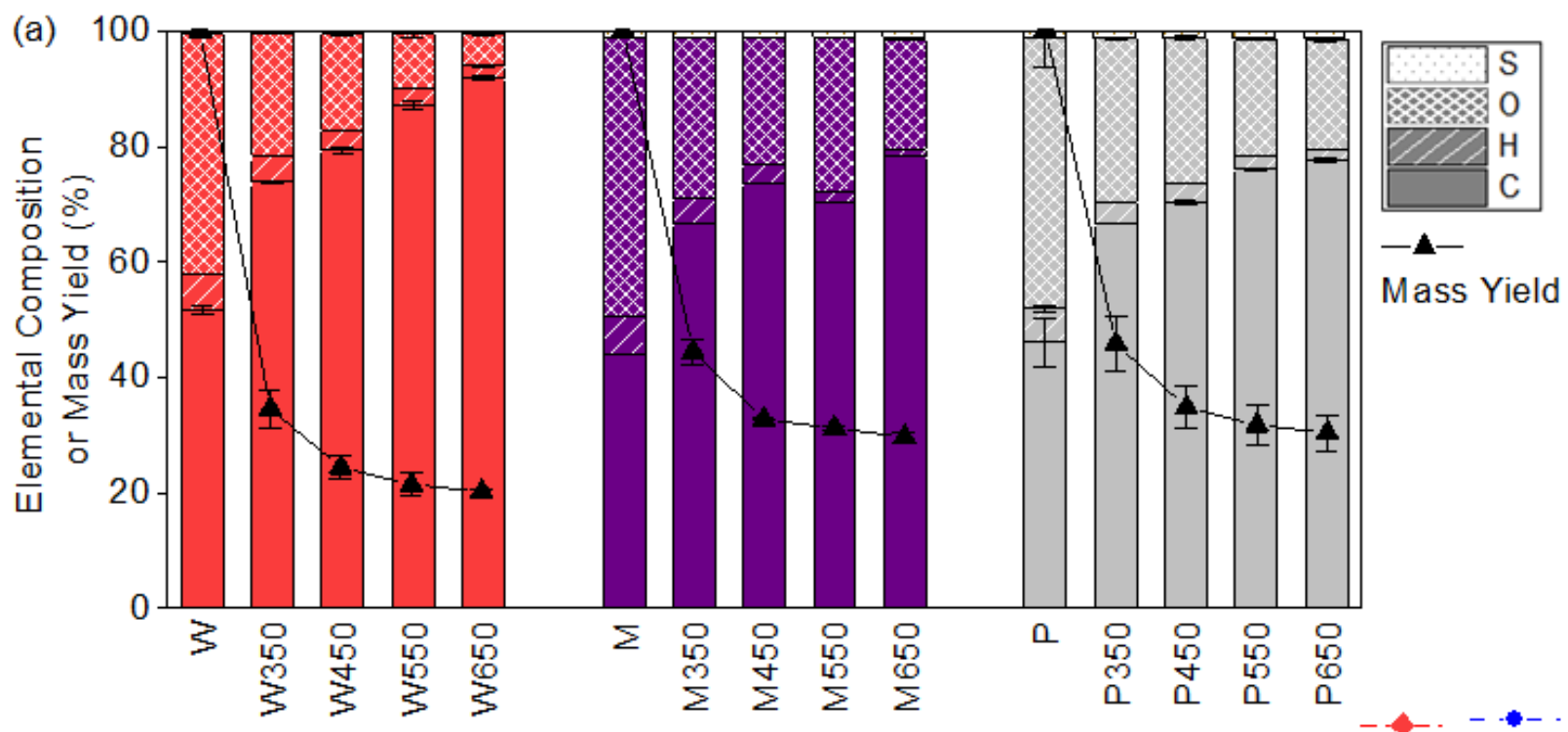

$[\mathrm{O}] /[\mathrm{C}][\mathrm{H}] /[\mathrm{C}]$

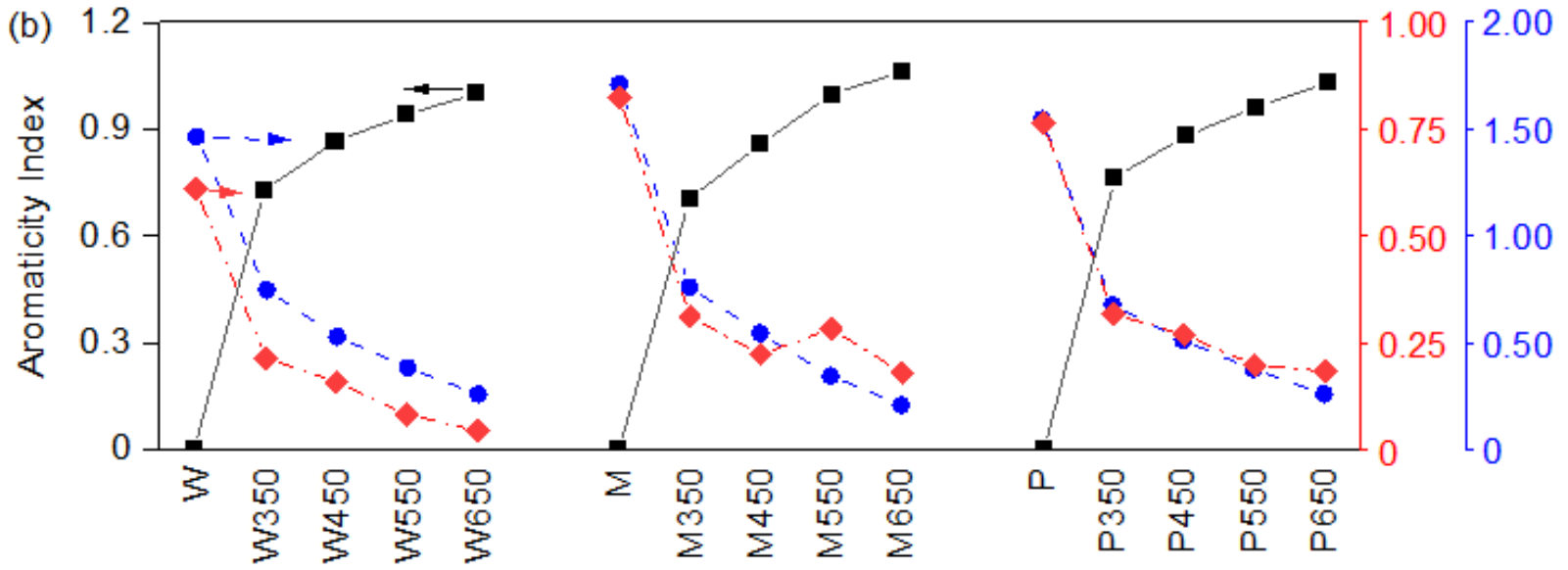

Figure S5. Characterization of wood, biopolymer mixture, and corresponding biochars from wood or biopolymer mixture pyrolysis. (a) Elemental composition (stacked columns) and massbased yield. (b) Aromaticity index and mole ratios of O/C and H/C. P stands for "predicted", showing values calculated based on the yield and characterization results of biochars made from individual biopolymers (Figure S4). Error bars represent the range of results from duplicates. 


\section{Section S4. Temperature dependency of ESC}

The ESC of biochar have been attributed to (hydro)quinone groups, the creation of which is favorable at medium pyrolysis temperatures (around $500{ }^{\circ} \mathrm{C}$ ), as suggested by $\mathrm{K}$-edge nearedge X-ray absorption fine structure (NEXAFS) spectra. ${ }^{7,8}$ Interestingly, the temperature dependency of ESC was different for different biopolymers. While xylan biochars exhibited the highest ESC at $550{ }^{\circ} \mathrm{C}$, the temperature dependencies of cellulose and lignin biochars are less clear. Cellulose is a linear polysaccharide that decomposes in a narrow temperature range (325$450{ }^{\circ} \mathrm{C}$ ) under nitrogen, ${ }^{9}$ whereas xylan and lignin are a branched polysaccharide and threedimensional cross-linked phenylpropane units, respectively, that exhibit a wider decomposition temperature range of $200-500{ }^{\circ} \mathrm{C}^{10}$. As pyrolysis temperature increases, hemicellulose generally decomposes first, followed by cellulose, and then lignin, which decomposes over a wide temperature range. ${ }^{10,11}$ These biopolymers may undergo dehydration, bond-cleavage, vaporization and condensation, cracking, cross-linkage, repolymerization and/or rearrangement, all of which might take place at different temperatures for different biopolymers and affect the molecular mechanism for ESC creation. The temperature dependency of wood was similar to those of cellulose and lignin. This similarity is due to the fact that cellulose and lignin exhibited a similar temperature dependence when pyrolyzed separately and together comprised more than $85 \%$ of the wood (Figure S6). 
Supporting Information
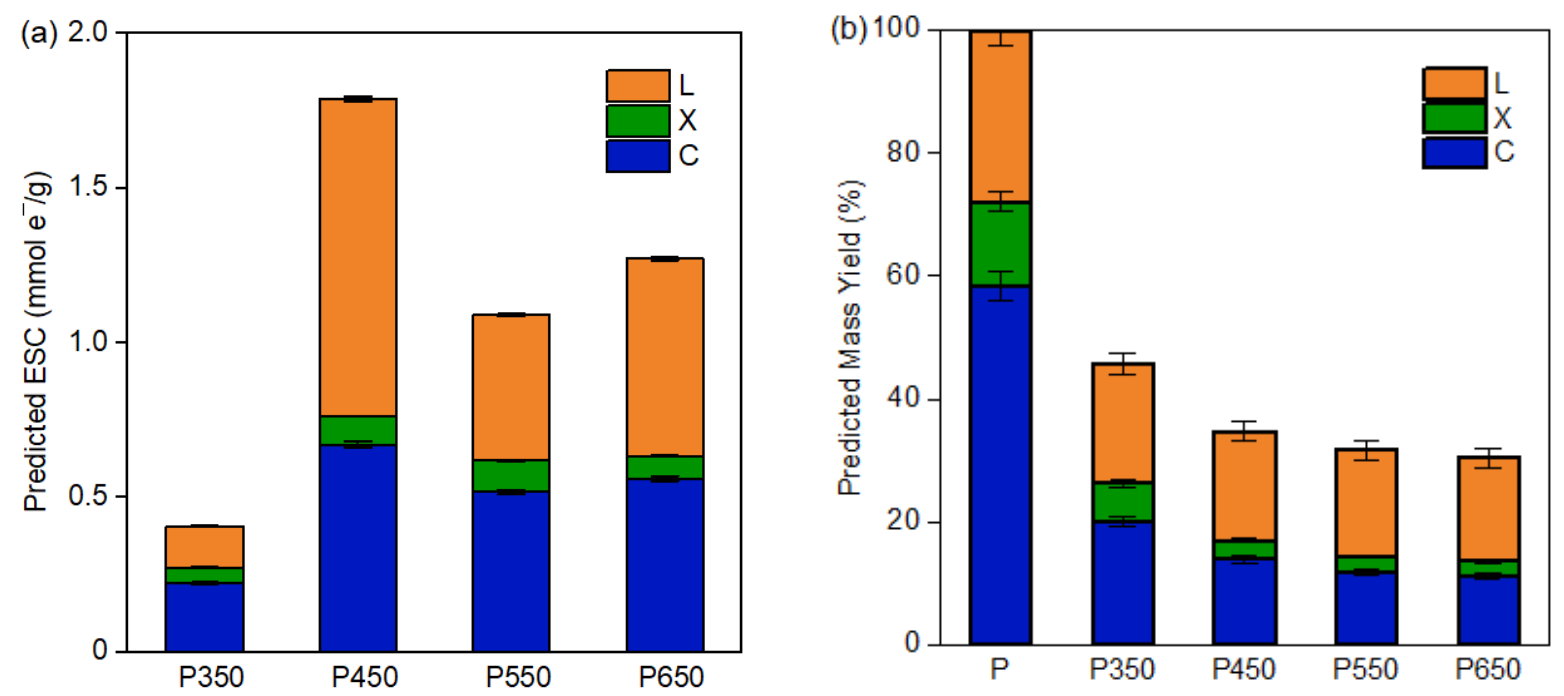

Figure S6. The contribution of each biopolymer to predicted (a) first cycle ESC and (b) mass yields. Note that panels (a) and (b) are calculated based on Eq. 3 and Eq. 5, equivalent to the third group (i.e., bars in gray) in Figure 4(a) and Figure S5(a), respectively. Error bars represent the range of results from duplicates. 
Supporting Information

\section{Section S5. Solid-state ${ }^{13} \mathrm{C}-\mathrm{NMR}$ spectroscopy}

Solid-state ${ }^{13} \mathrm{C}$ NMR (ss-NMR) is a powerful tool for investigating complex environmental samples, as it enables nondestructive, comprehensive, and quantitative analyses of intact solid samples such as plant materials and biochar. ${ }^{12}$ The advanced multiple cross-polarization $(\mathrm{CP})$ is a new and robust quantitative ${ }^{13} \mathrm{C}$ technique for the characterization of unlabeled solids with at least 50 times shorter measurement time yet uncompromised sensitivity than previously achieved in direct-polarization NMR. ${ }^{13}$ The multiple CP ss-NMR with ramp CP at 14-kHz MAS has been successfully validated for plant matter, humic acids, and biochar. ${ }^{13,14}$

NMR spectra were collected on a Bruker AVIII 500 MHz spectrometer (Billerica, MA) with a $4 \mathrm{~mm} \mathrm{HX}$ probe at a spinning speed of $14 \mathrm{kHz}$ and frequency of $125.770 \mathrm{MHz}$. Multiple $\mathrm{CP}$ magic angle spinning (MAS) was used to obtain quantitative peak intensities with a total $\mathrm{CP}$ time of $10.45 \mathrm{~ms}$ and a repolarization delay of $125 \mathrm{~ms}$ between CP blocks. 3328 scans were acquired over $4 \mathrm{~h}$ with a recycle delay of $2 \mathrm{~s}$. We also ran 19968 scans over $24 \mathrm{~h}$ for selected samples and observed no discernible difference in the relative content of functional groups (data not shown). All sample spectra were calibrated to a glycine external standard. Two reference compounds, 1,4-benzoquinone (BQ) and 1,4-hydroquinone (HQ), were added to confirm shift ranges of (hydro)quinoic functional groups in samples (Figure S7). ss-NMR spectra (Figure S8) were baseline-corrected, divided into chemical shift ranges of carbon functional groups typical of biochar $^{14}$, and peak integrated using MestreNova (Mestrelab Research S.L., A Coruña, Spain). Carbon content (\%) of functional groups in each sample was calculated and reported in Table S6. 
Supporting Information

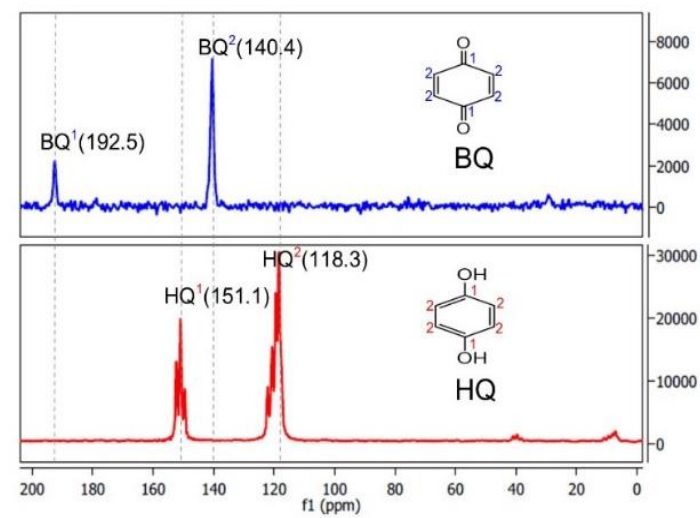

Figure S7. ss-NMR spectra of reference compounds including BQ and HQ.

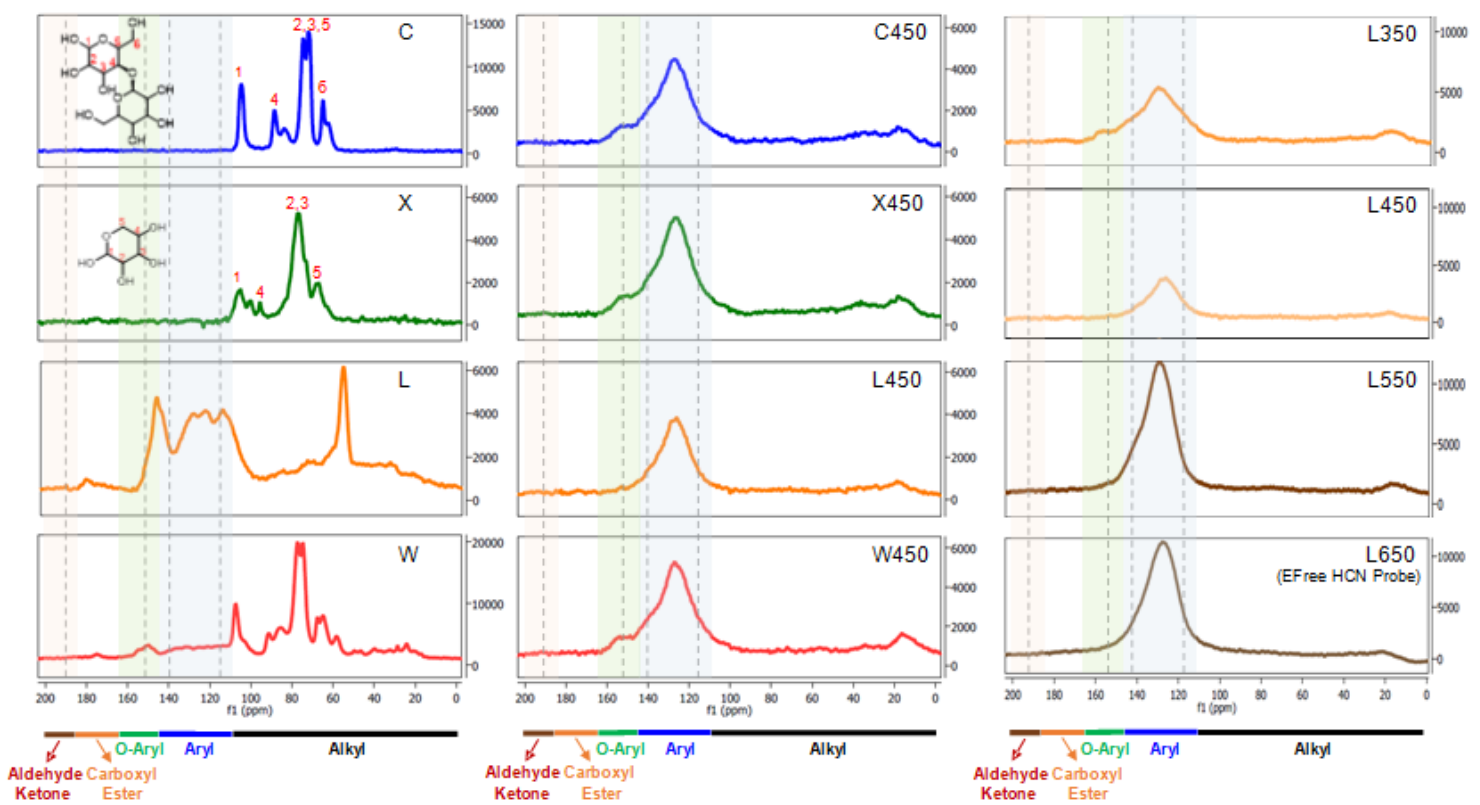

Figure S8. ss-NMR spectra of feedstocks (cellulose, xylan, lignin, and wood), biochars prepared at $450{ }^{\circ} \mathrm{C}$, and biochars derived from lignin at different pyrolysis temperatures. The regions of carbon groups that are potentially redox-active, namely aldehyde/ketone-C, O-aryl-C, aryl-C, are shaded using different background colors and the peak positions of two reference compounds (BQ and HQ, Figure S7) are specified in dotted vertical lines. 


\section{Supporting Information}

Table S6. Carbon content (\%) of functional groups in feedstocks and biochars calculated from ss-NMR spectra (Figure S8)

\begin{tabular}{|c|c|c|c|c|c|c|c|c|}
\hline \multirow[t]{4}{*}{ Sample } & \multicolumn{2}{|c|}{ Carbonyl-C } & \multicolumn{2}{|c|}{ Total Aryl-C } & \multicolumn{4}{|c|}{ Alkyl-C } \\
\hline & 220-184 ppm & 184-165 ppm & $165-146 \mathrm{ppm}$ & $146-110 \mathrm{ppm}$ & $110-90 \mathrm{ppm}$ & $90-45 \mathrm{ppm}$ & 45-20 ppm & 20-0 ppm \\
\hline & Aldehyde/Ketone & Carboxyl/Ester & $\begin{array}{c}\text { Oxygenated } \\
\text { Aromatic }\end{array}$ & Aromatic & $\begin{array}{c}\text { Dioxygenated } \\
\text { Alkyl }\end{array}$ & $\begin{array}{c}\text { Oxygenated } \\
\text { Alkyl }\end{array}$ & Methylene & Methyl \\
\hline & $\mathrm{RC}=\mathrm{O}$ & RCOOR & Ar-OR & $\mathrm{C}=\mathrm{C} / \mathrm{Ar}-\mathrm{C}-\mathrm{H}$ & RO-C-OR & $\mathrm{RCH}_{2}-\mathrm{OR}$ & $\mathrm{CH}_{2}$ & $\mathrm{CH}_{3}$ \\
\hline $\mathrm{C}$ & 0.00 & 0.12 & 0.00 & 0.00 & 18.22 & 81.29 & 0.38 & 0.00 \\
\hline$X$ & 0.29 & 0.27 & 0.00 & 0.00 & 19.52 & 79.16 & 0.76 & 0.00 \\
\hline $\mathrm{L}$ & 1.14 & 2.05 & 6.91 & 41.52 & 8.58 & 26.97 & 9.89 & 2.94 \\
\hline W & 0.00 & 0.00 & 1.23 & 7.83 & 13.71 & 74.05 & 3.18 & 0.00 \\
\hline $\mathrm{C} 450$ & 2.25 & 2.21 & 8.20 & 55.95 & 5.96 & 9.29 & 9.68 & 6.46 \\
\hline $\mathrm{X} 450$ & 2.23 & 1.99 & 7.85 & 56.47 & 5.94 & 9.56 & 9.42 & 6.55 \\
\hline L450 & 0.00 & 1.21 & 3.65 & 68.86 & 5.18 & 8.22 & 7.73 & 5.14 \\
\hline W450 & 3.28 & 2.85 & 7.84 & 52.39 & 7.09 & 10.31 & 7.56 & 8.68 \\
\hline L350 & 6.22 & 4.60 & 9.52 & 44.25 & 6.97 & 12.07 & 8.95 & 7.42 \\
\hline L550 & 4.48 & 3.61 & 6.60 & 61.55 & 5.31 & 9.23 & 4.57 & 4.64 \\
\hline L650 & 5.99 & 4.44 & 7.17 & 60.61 & 6.81 & 8.86 & 4.85 & 1.27 \\
\hline
\end{tabular}


Table S7. Reported EDC and EAC (mmol e/g) of plant-based biochar measured using MEO and MER, respectively.

\begin{tabular}{|c|c|c|c|c|c|c|c|c|c|c|c|c|}
\hline & \multicolumn{3}{|c|}{$\begin{array}{l}\text { Klüpfel et al., } 2014 \\
\text { Environmental Science \& } \\
\text { Technology }\end{array}$} & \multicolumn{3}{|c|}{$\begin{array}{l}\text { Chacón et al., } 2020 \\
\text { Chemical Engineering Journal }\end{array}$} & \multicolumn{3}{|c|}{$\begin{array}{l}\text { Wang et al., } 2020 \\
\text { Environmental Science \& } \\
\text { Technology } y^{16}[23]\end{array}$} & \multicolumn{3}{|c|}{$\begin{array}{l}\text { Li et al., } 2020 \\
\text { Journal of Hazardous } \\
\text { Materials }^{8[34]}\end{array}$} \\
\hline Feedstocks & \multicolumn{3}{|c|}{$\begin{array}{l}\text { Ponderosa pine }(\mathrm{W}) \text { and tall } \\
\text { fescue grass }(\mathrm{G})\end{array}$} & \multicolumn{3}{|c|}{$\begin{array}{l}\text { Olive tree (OLW), almond tree } \\
(\text { ALW }), \text { and orange tree }(\text { ORW })\end{array}$} & \multicolumn{3}{|c|}{ Rice straw (RS) } & \multicolumn{3}{|c|}{$\begin{array}{l}\text { Cellulose }(\mathrm{C}) \text { and lignin } \\
(\mathrm{L})\end{array}$} \\
\hline \multirow{14}{*}{$\begin{array}{l}\text { Pyrolysis } \\
\text { Conditions }\end{array}$} & \multicolumn{3}{|c|}{$1 \mathrm{~h}$ under atmosphere } & \multicolumn{3}{|c|}{$2 \mathrm{~h}$ under $\mathrm{Ar}$} & \multicolumn{3}{|c|}{$4 \mathrm{~h}$ under $\mathrm{N}_{2}$} & \multicolumn{3}{|c|}{$1 \mathrm{~h}$ under $\mathrm{N}_{2}$} \\
\hline & $\mathrm{T}$ & EDC & EAC & $\mathrm{T}$ & $\mathrm{EDC}^{*}$ & $\mathrm{EAC}^{*}$ & $\mathrm{~T}$ & $\mathrm{EDC}^{*}$ & EAC $^{*}$ & $\mathrm{~T}$ & $\mathrm{EDC}^{*}$ & $\mathrm{EAC}^{*}$ \\
\hline & W200 & 0.15 & 0.005 & OLW400 & 0.24 & 0.17 & RS250 & 0.04 & 0.03 & $\mathrm{C} 300$ & 0.13 & 0.03 \\
\hline & W300 & 0.2 & 0.02 & OLW600 & 0.15 & 0.20 & RS350 & 0.04 & 0.04 & $\mathrm{C} 500$ & 0.12 & 0.18 \\
\hline & W400 & 0.2 & 0.26 & OLW800 & 0.04 & 0.07 & RS450 & 0.03 & 0.08 & $\mathrm{C} 700$ & 0.09 & 0.27 \\
\hline & W500 & 0.03 & 0.54 & OLW1000 & 0.03 & 0.03 & RS550 & 0.01 & 0.10 & L300 & 0.24 & 0.01 \\
\hline & W600 & 0.03 & 0.15 & ALW400 & 0.23 & 0.09 & RS650 & 0.02 & 0.10 & L500 & 0.43 & 0.30 \\
\hline & W700 & 0.03 & 0.22 & ORW400 & 0.26 & 0.43 & RS750 & 0.01 & 0.08 & L700 & 0.34 & 0.67 \\
\hline & G200 & 0.12 & 0.02 & & & & RS850 & 0.01 & 0.07 & & & \\
\hline & G300 & 0.34 & 0.06 & & & & RS950 & 0.01 & 0.05 & & & \\
\hline & G400 & 0.7 & 0.9 & & & & & & & & & \\
\hline & G500 & 0.24 & 0.8 & & & & & & & & & \\
\hline & G600 & 0.1 & 0.61 & & & & & & & & & \\
\hline & G700 & 0.11 & 0.75 & & & & & & & & & \\
\hline
\end{tabular}

"Values were obtained by digitizing figures using Engauge Digitizer.

[reference number] represents reference numbers in the main text. 
Supporting Information

\section{References}

1. Gomez-Eyles, J. L.; Yupanqui, C.; Beckingham, B.; Riedel, G.; Gilmour, C.; Ghosh, U., Evaluation of biochars and activated carbons for in situ remediation of sediments impacted with organics, mercury, and methylmercury. Environ. Sci. Technol. 2013, 47, (23), 13721-13729. DOI 10.1021/es403712q.

2. The California Department of Forestry and Fire Protection (CAL FIRE). https://www.fire.ca.gov/incidents/2019/

3. Falandysz, J.; Chudzyński, K.; Kojta, A. K.; Jarzyńska, G.; Drewnowska, M., Comparison of two acid extraction methods for determination of minerals in soils beneath to Larch Bolete (Suillus grevillei) and aimed to estimate minerals sequestration potential in fruiting bodies. J. Environ. Sci. Health A Part A 2012, 47, (11), 1607-1613. DOI 10.1080/10934529.2012.680781.

4. Koch, B. P.; Dittmar, T., From mass to structure: an aromaticity index for high-resolution mass data of natural organic matter. Rapid Commun. Mass Spectrom. 2006, 20, (1), 926-936. DOI 10.1002/rcm.2386.

5. Dondi, D.; Zeffiro, A.; Speltini, A.; Tomasi, C.; Vadivel, D.; Buttafava, A., The role of inorganic sulfur compounds in the pyrolysis of Kraft lignin. J. Anal. Appl. Pyrolysis 2014, 107, 53-58. DOI 10.1016/j.jaap.2014.02.002.

6. Evdokimov, A. N.; Kurzin, A. V.; Fedorova, O. V.; Lukanin, P. V.; Kazakov, V. G.; Trifonova, A. D., Desulfurization of kraft lignin. Wood Sci. Technol. 2018, 52, (4), 1165-1174. DOI 10.1007/s00226-018-1014-1. 
Supporting Information

7. Klüpfel, L.; Keiluweit, M.; Kleber, M.; Sander, M., Redox properties of plant biomassderived black carbon (biochar). Environ. Sci. Technol. 2014, 48, (10), 5601-5611. DOI 10.1021/es500906d.

8. Li, S.; Shao, L.; Zhang, H.; He, P.; Lu, F., Quantifying the contributions of surface area and redox-active moieties to electron exchange capacities of biochar. J. Hazard. Mater. 2020, 394, 122541. DOI 10.1016/j.jhazmat.2020.122541.

9. Shen, D. K.; Gu, S., The mechanism for thermal decomposition of cellulose and its main products. Bioresour. Technol. 2009, 100, (24), 6496-6504. DOI 10.1016/j.biortech.2009.06.095. 10. Yu, J.; Paterson, N.; Blamey, J.; Millan, M., Cellulose, xylan and lignin interactions during pyrolysis of lignocellulosic biomass. Fuel 2017, 191, 140-149. DOI 10.1016/j.fuel.2016.11.057.

11. Zhao, C. X.; Jiang, E. C.; Chen, A. H., Volatile production from pyrolysis of cellulose, hemicellulose and lignin. J. Energy Inst. 2017, 90, (6), 902-913. DOI 10.1016/j.joei.2016.08.004. 12. Mao, J. D.; Cao, X. Y.; Olk, D. C.; Chu, W. Y.; Schmidt-Rohr, K., Advanced solid-state NMR spectroscopy of natural organic matter. Prog. Nucl. Magn. Reson. Spectrosc. 2017, 100, 17-51. DOI 10.1016/j.pnmrs.2016.11.003.

13. Johnson, R. L.; Schmidt-Rohr, K., Quantitative solid-state C-13 NMR with signal enhancement by multiple cross polarization. J. Magn. Reson. 2014, 239, 44-49. DOI 10.1016/j.jmr.2013.11.009.

14. Bostick, K. W.; Zimmerman, A. R.; Wozniak, A. S.; Mitra, S.; Hatcher, P. G., Production and composition of pyrogenic dissolved organic matter from a logical series of laboratorygenerated chars. Front. Earth Sci. 2018, 6, pp. 14. DOI 10.3389/feart.2018.00043. 
Supporting Information

15. Chacón, F. J.; Sanchez-Monedero, M. A.; Cayuela, M. L.; Lezama, L., Enhancing biochar redox properties through feedstock selection, metal preloading and post-pyrolysis treatments. Chem. Eng. J. 2020, 395, 125100. DOI 10.1016/j.cej.2020.125100.

16. Wang, H.; Zhao, H. P.; Zhu, L., Role of pyrogenic carbon in parallel microbial reduction of nitrobenzene in the liquid and sorbed phases. Environ. Sci. Technol. 2020, 54, 8760-8769.

DOI 10.1021/acs.est.0c01061. 